\title{
Estágio Curricular Supervisionado no Curso Interdisciplinar em Educação do Campo: desafios e possibilidades
}

\section{Supervised curricular internship of the interdisciplinary course in rural education: challenges and possibilities}

\author{
Lucineia Lopes (lucineialopes24@gmail.com) \\ Acadêmica do Curso Interdisciplinar em Educação do Campo: Ciências da Natureza da Universidade \\ Federal da Fronteira Sul - UFFS - Campus de Erechim
}

Fernanda Teresa Moro (fernanda.moro@uffs.edu.br)

Professora Substituta do Curso Interdisciplinar em Educação do Campo: Ciências da Natureza da Universidade Federal da Fronteira Sul - UFFS Campus de Erechim

Lisandra Almeida Lisovski (lisandra.lisovski@uffs.edu.br)

Professora Adjunta do Curso Interdisciplinar em Educação do Campo: Ciências da Natureza da Universidade Federal da Fronteira Sul - UFFS - Campus de Erechim

Resumo: Este trabalho objetiva investigar os desafios e dificuldades que os acadêmicos estagiários do Curso Interdisciplinar em Educação do Campo: Ciências da Natureza Licenciatura da Universidade Federal da Fronteira Sul - UFFS Campus Erechim, apresentam durante o estágio IV, bem como se as atividades experimentais fazem parte de seus planejamentos nos referidos estágios. Buscamos respostas para o seguinte problema: Quais os desafios e dificuldades que os acadêmicos enfrentam durante a elaboração do planejamento do estágio supervisionado no ensino médio? A abordagem metodológica desenvolvida é qualitativa. A análise dos dados, coletados junto aos acadêmicos que realizaram o estágio IV (primeiro semestre 2019), incluiu um questionário com perguntas abertas, a partir do qual foram elaboradas categorias de respostas, analisadas conforme proposições da Teoria Fundamentada de Charmaz (2009). Como resultados apontamos dificuldade dos estagiários na articulação das disciplinas de biologia, física e química, com seus respectivos conteúdos de forma interdisciplinar. Os resultados apontam a necessidade de olhares diferenciados para a formação inicial em um curso interdisciplinar, promovendo o enriquecimento dos planejamentos, bem como contemplar a interdisciplinaridade e o uso de atividades experimentais em componentes curriculares do curso e nos estágios supervisionados, para que ambas possam efetivamente permear e enriquecer a práxis do futuro professor.

Palavras-chave: Estágio Curricular; Ensino de Ciências; Educação do Campo.

\begin{abstract}
The present work aims to investigate the challenges and difficulties which the academic trainees from the Interdisciplinary Course in Rural Education: Natural Sciences - Licentiate Degree from Universidade Federal da Fronteira Sul - UFFS Campus Erechim, present during the discipline of Internship level IV, as well as if the experimental activities are part of their planning on the referred internship period. We pursue the answers to the following problem: Which challenges and difficulties the academics face during the elaboration of the planning for the high-school supervised internship (Internship level IV)? The methodological approach implemented is qualitative. The analyses of the data collected from the academics which carried out the
\end{abstract}


internship in the referred course in the (first semester of 2019), included a questionnaire with open questions applied to them, from which response categories were elaborated, that were analyzed according to the proposal of the Grounded Theory of Charmaz (2009). From the results it can be noticed that there is a difficulty on the part of the trainees on the articulation of the disciplines of Biology, Physics and Chemistry, together with their respective contents, in an interdisciplinary manner. The results from the research point out the need for differentiated approaches on the initial formation of teachers in an interdisciplinary course, which come to promote the enrichment of their lesson planning, as well as to contemplate the interdisciplinarity and the usage of experimental activities in curricular components of the course and on the supervised internships, so that both could effectively permeate and enrich the praxis of the future teacher.

Key-words: Curricular Internship; Science Education; Rural Education.

\section{INTRODUÇÃO}

A Formação Inicial de professores e, em especial, o Estágio Curricular são pautas de inúmeras discussões e debates, tanto nas Instituições de Ensino Superior (IES) quanto em encontros, seminários e congressos envolvendo professores, acadêmicos e pesquisadores da área.

Esses debates intensificaram-se após a promulgação da Lei de Diretrizes e Bases da Educação Nacional (LDB - Lei no 9.394/96), e, posteriormente com a promulgação da Resolução do Conselho Nacional de Educação (CNE), de 18 de fevereiro de 2002, que indicava o compartilhamento entre IES e as Escolas de Educação Básica (EEB) na responsabilidade pelo planejamento, desenvolvimento e avaliação em ações de Formação Inicial de professores e a Resolução CNE 2/2002, que regulamentava a duração e a carga horária dos Cursos de Licenciatura e mais recentemente com a publicação da Resolução CNE/CP 02/2015, que definiu as Diretrizes Curriculares Nacionais para a formação inicial em nível superior (cursos de licenciatura, cursos de formação pedagógica para graduados e cursos de segunda licenciatura) e para a formação continuada.

Apesar da Resolução CNE/CP 02/2015 aumentar a carga-horária dos cursos de licenciatura de 2.800 horas (Resolução CNE/CP 02/2015) para 3.200 horas e definir o tempo de integralização em 8 semestres, a carga horária destinada aos estágios curriculares supervisionados se manteve inalterada. O artigo 13 da Resolução CNE/CP 02/2015, ainda prevê que 
[...] formação para o exercício integrado e indissociável da docência na educação básica, incluindo o ensino e a gestão educacional, e dos processos educativos escolares e não escolares, da produção e difusão do conhecimento científico, tecnológico e educacional. (BRASIL, 2015, p. 89).

Neste sentido, o Estágio Curricular Supervisionado é importante na carreira de qualquer professor. É o espaço formativo oficial do futuro professor. Desse modo, tanto as IES como as EEB precisam estar cientes de sua tarefa enquanto instituição formadora. As EEB também precisam sentir-se co-responsáveis neste processo, não sendo apenas uma instituição que recebe e acolhe alunos estagiários.

As pesquisas desenvolvidas por Terrazzan (2003) evidenciam que a Formação Inicial de professores, sobretudo para o Ensino Médio, é vista como de exclusiva responsabilidade das IES. As escolas esperam que os docentes das Universidades, professores orientadores de estágio, visitem os alunos estagiários nas salas de aula, procedendo às "correções" necessárias para o bom andamento das aulas. Com isso, a escola formalmente se "desobriga" em relação à formação daqueles que serão seus futuros profissionais.

O papel dos professores regentes de turma das EEB vai além de repassar ao estagiário uma lista de conteúdos a serem desenvolvidos e as normas da escola, as quais devem ser seguidas para o bom andamento das aulas. Os professores precisam ser envolver também na tarefa de acompanhamento dos futuros professores.

Sabemos que no processo de Formação Inicial de professores existem atribuições inerentes a cada uma das instituições de ensino envolvidas. A escola é o espaço onde os acadêmicos poderão vivenciar situações "reais" de trabalho em seu Estágio Curricular, pois é no exercício da profissão que se consolida o processo de tornar-se professor, ou seja, o aprendizado da profissão a partir de seu exercício possibilita configurar como vai sendo construído o processo de aprender a ensinar. Tal construção ocorre à medida que o professor vai efetivando a articulação entre os conhecimentos teórico-acadêmicos e o contexto escolar com a prática docente (LISOVSKI, 2006).

Lisovski (2006) defende que cabe ao professor orientador de estágio da Universidade, ao professor regente de turma e aos membros das equipes diretivas ajudar os licenciandos a se tornarem mais conscientes dos conhecimentos que já possuem, além de estimular diferentes formas de reflexão, ampliando o processo de problematização da sua própria prática.

Levando em consideração a importância dos Estágio Curriculares Supervisionados, este trabalho objetiva identificar os principais desafios/dificuldades 
dos acadêmicos do Curso Interdisciplinar em Educação do Campo: Ciências da Natureza.

Assim, buscamos respostas para o seguinte problema: Quais os desafios e as dificuldades que os acadêmicos da Licenciatura Interdisciplinar em Educação do Campo - Ciências da Natureza da Universidade Federal da Fronteira Sul - UFFS - Erechim enfrentam durante a elaboração do planejamento do Componente Curricular denominado Estágio Supervisionado no Ensino Médio (Estágio IV)?

O referido estágio tem por objetivo oportunizar experiências e vivências no cotidiano da sala de aula do Ensino Médio; permite a integração entre teoria e prática, estabelecendo o contato com o estudante e com a vida profissional no contexto escolar, organizando situações de ensino interdisciplinares com o uso de recursos e estratégias teórico - práticas indispensáveis à aprendizagem e ao desempenho da atividade docente.

Durante a realização deste estágio, o futuro professor realiza as seguintes atividades:

a) ministra aulas nas disciplinas de Biologia, Física e Química interdisciplinarmente numa turma de alunos de Ensino Médio;

b) participa de aulas teóricas e de encontros de orientação e planejamento do estágio;

c) elabora planos de ensino e de aulas;

d) elabora um relatório de estágio;

d) compartilha as experiências vivenciadas em um Seminário Final de Estágio, no qual participam os acadêmicos do curso em situação de estágio, os professores orientadores de estágio e os professores regentes das escolas campo de estágio.

\section{A IMPORTÂNCIA DOS ESTÁGIOS CURRICULARES SUPERVISIONADOS NO PROCESSO DE FORMAÇÃO DE PROFESSORES}

Fazendo um breve resgate histórico dos cursos de licenciatura, Pereira (1999, p. 111) aponta que no Brasil as primeiras licenciaturas foram decorrentes das antigas faculdades de filosofia dos anos 30. "Elas constituíram-se segundo a fórmula " $3+1$ ", em que as disciplinas de natureza pedagógica, cuja duração prevista era de um ano, justapunham-se às disciplinas de conteúdo, com duração de três anos." 
O autor, ainda destaca que essa estrutura organizacional dos cursos de licenciatura ficou conhecida como modelo da racionalidade técnica, onde o professor era visto apenas como um especialista que aplicava os conhecimentos científicos e pedagógicos na sua prática cotidiana.

Essas matrizes curriculares dos cursos de licenciatura reforçavam uma concepção fragmentada da formação em que a sala de aula era o espaço para a teoria e o campo profissional era o espaço para a prática. Fator este que acabava contribuindo para a efetiva desarticulação entre teoria e a prática.

Já nas décadas de 1960, 1970 e 1980, os estudos de Tanuri (2000) apontaram que a realização do Estágio Curricular Supervisionado nos cursos de licenciatura se concentrava nos seus aspectos burocráticos (cumprimento de horários, preenchimento de fichas, confecção de relatórios, entre outros). E ainda, eram ofertados nos últimos semestres e junto com eles, um aglomerado de disciplinas consideradas práticas, tais como: as Didáticas, as Metodologias do Ensino, as Práticas de Ensino.

Dessa forma, o Estágio Curricular Supervisioando ficava, em certa medida, desvinculado do restante do Curso, sendo considerado, em muitos casos, uma mera disciplina obrigatória que deveria ser cumprida pelos estagiários para a obtenção do diploma. Isso não poderia ser diferente, pois o currículo dos cursos de formação de professores não valorizava as disciplinas consideradas práticas.

Essa forma de organização dos cursos de licenciatura gerou alguns problemas, dentre eles, podemos citar, a dicotomia entre a teoria e a prática, a separação entre as disciplinas conceituais e as disciplinas pedagógicas e Licenciatura X Bacharelado. Ranços desses problemas ainda persistem nos dias atuais, uma vez que as disciplinas ditas "conceituais" são consideradas mais importantes do que as disciplinas "pedagógicas". Como se as disciplinas pedagógicas não possuíssem aportes teóricos conceituais.

Esses ranços podem ser visualizados claramente nos estudos realizados por Bittar e Nogueira (2015). Os pesquisadores analisaram as estruturas curriculares de cursos de licenciatura na Universidade Federal do Mato Grosso do Sul - UFMS, em especial do Campus Campo Grande e identificaram diminuição da oferta de disciplinas pedagógicas, a dicotomia entre as disciplinas de conteúdo específico e as de conteúdo didático-pedagógico, como ocorre também, de modo geral, em outras Licenciaturas.

O Estágio Curricular Supervisionado não pode ser único momento de integração entre o curso e o campo de estágio. É imprescindível a articulação entre as Instituição de 
Ensino Superior (IES) e as Escolas de Educação Básica (EEB), justamente para romper com a dicotomia existente entre a teoria e a prática.

Buscando superar essa desarticulação entre IES e EEB, a Resolução CNE/CP 2/2002 determina a realização de 400 horas de Prática de Ensino como componente curricular a ser realizado desde o início do curso e 400 horas de Estágio Curricular a serem desenvolvidas a partir do início da segunda metade do Curso de Licenciatura.

Assim, essa resolução buscou antecipar o contatos dos futuros professores com as escolas campo de estágio, realizando nestes espaços formativos diferentes atividades, dentre elas, podemos citar: conhecer a realidade escolar, assistir às aulas de professores regentes de turma, planejar e ministrar oficinas pedagógicas, elaborar e implementar projetos, entre outras (LISOVSKI, 2006).

É possível verificar ainda, avanços na concepção de Estágio presente nas normativas legais, pois o Parecer 21, de 2001, do Conselho Nacional de Educação, define o Estágio Curricular como um

[...] tempo de aprendizagem que, através de um período de permanência, alguém se demora em algum lugar ou ofício para aprender a prática do mesmo e depois poder exercer uma profissão ou ofício. Assim o estágio supõe uma relação pedagógica entre alguém que já é um profissional reconhecido em um ambiente institucional de trabalho e um aluno estagiário [...] é o momento de efetivar um processo de ensino/aprendizagem que, tornar-se-á concreto e autônomo quando da profissionalização deste estagiário (BRASIL, 2001, p. 120).

Dessa forma, compreender o Estágio Curricular Supervisionado como um tempo destinado a um processo de ensino e de aprendizagem é reconhecer que, apesar de a formação oferecida em sala de aula ser fundamental, sozinha ela não é suficiente para preparar os futuros professores para o pleno exercício de sua profíssão. Faz-se necessária a inserção do licenciando na realidade do cotidiano escolar, o que é proporcionado não só, mas fundamentalmente, pelo Estágio e pela Prática de Ensino como componente curricular (LISOVSKI, 2006).

Assim, consideramos que os Estágios são uma forma de introduzir o licenciando na escola, com auxílio de professores experientes que possam orientá-lo e auxiliá-lo na solução das dificuldades que venham a surgir ao longo de sua prática. Concordamos com Lisovski (2006) quando a autora defende que a realização do Estágio Curricular Supervisionado é fundamental na carreira de qualquer professor, pois ele pode se constituir em um momento em que os estagiários podem estar mais sensíveis e receptivos às sugestões de colegas e uma orientação adequada neste período poderia contribuir para aquisição de maior confiança e dedicação ao longo de sua carreira. 
A experiência profissional só é construída na medida que os licenciandos vivenciam sua profissão. Neste sentido, as IES têm papel fundamental no processo de fornecer um espaço/tempo privilegiado para diálogo e análise crítica das ações realizadas pelos licenciandos nas escolas campo de estágio.

Com o intuito de aproximar o aluno da realidade da escola e superar a dicotomia entre a teoria e a prática, acreditamos na realização de um Estágio Curricular reflexivo, no qual o licenciando possa ter a oportunidade de conhecer e compreender a realidade da escola e da turma de alunos em que vai estagiar, que possa ter a oportunidade de refletir sobre as atividades desenvolvidas com seus alunos, que possa ter a oportunidade de desenvolver trabalhos coletivos com outros professores que compõem o corpo docente da escola, entre outras atividades.

O Estágio Curricular supervisionado é um espaço para construção de saberes práticos e teóricos; de consolidação de formas de interagir com as situações imprevisíveis características dessa prática profissional; de sistematização conhecimentos; identificação de dilemas e condicionantes; análise das intervenções feitas; de propor mecanismos de solução; de construção e mobilização saberes docentes.

Neste sentido, apostamos que para formar o futuro professor é importante a participação de todos os atores envolvidos com a realização deste tipo de Estágio, ou seja, o envolvimento de professores orientadores de estágio das IES, de professores regentes de turma das EEB e de membros das equipes diretivas das EEB.

\section{METODOLOGIA}

Para este trabalho optou-se pela pesquisa qualitativa que teve como fonte de informação os acadêmicos que cursavam o CCR denominado "Estágio Supervisionado no Ensino Médio (Estágio IV)" do curso Interdisciplinar em Educação do Campo: Ciências da Natureza da Universidade Federal da Fronteira Sul - UFFS - Campus Erechim. As informações foram coletadas durante o primeiro semestre do ano de 2019, mediante a aplicação de um questionário com perguntas abertas. Todos os seis acadêmicos matriculados no CCR participaram da pesquisa.

A escolha pelo questionário, justifica-se pelo fato do Curso Interdisciplinar em Educação do Campo: Ciência da Natureza funcionar em regime de alternância (aulas do Tempo Universidade ocorriam a cada 15 dias) e os acadêmicos residiam em diferentes regiões dos estados do Rio Grande do Sul e Santa Catarina. Assim, o instrumento utilizado facilitou a coleta das informações. 
Após a devolutiva dos questionários aplicados, cada um recebeu um código com o objetivo de garantir o anonimato dos sujeitos participantes da pesquisa. Posteriormente cada questionário foi digitado na íntegra.

Os procedimentos adotados para organização e análise das informações coletadas foram:

a. Criação de um arquivo digital contendo as perguntas e as respostas dos acadêmicos envolvidos na pesquisa;

b. Criação de um quadro de análise para cada pergunta contida no questionário.

Este quadro estava organizado da seguinte forma: digitação do código de identificação do estudante na primeira coluna, as respostas dadas na íntegra, na segunda coluna, as ideias centrais dessas respostas na terceira coluna, e as categorias temáticas das respostas na quarta coluna.

c. Leitura das respostas para extrair as ideias centrais das mesmas;

d. Elaboração de categorias de respostas.

Para realizar o processo de tratamento das informações coletadas, bem como, a sua análise, utilizamos a técnica de categorização temática ou codificação descrita por Gibbs (2009), na qual o autor utiliza como base Teoria Fundamentada de Charmaz (2009). Charmaz (2009, p. 70) afirma que a codificação é o elo fundamental entre a coleta de dados e o desenvolvimento de uma teoria emergente para explicar esses dados.

Para extrair as ideias centrais das respostas e construir as categorias, foi necessário ler por diversas vezes as respostas obtidas.

\section{RESULTADOS E DISCUSSÕES}

Buscando identificar os principais desafios/dificuldades dos acadêmicos do Curso Interdisciplinar em Educação do Campo: Ciências da Natureza, aplicamos um questionário com oito perguntas abertas aos seis acadêmicos que estavam matriculados no componente curricular - CCR “Estágio Supervisionado no Ensino Médio (Estágio IV)" que corresponde ao último estágio de regência do curso.

Primeiramente buscamos saber quais foram as principais dificuldades encontradas no planejamento do último Estágio Curricular Supervisionado. Dentre as dificuldades apontadas, cinco dos seis acadêmicos apontaram a articulação entre os conteúdos que fazem parte das disciplinas que compõem a área curricular Ciências da Natureza (Biologia, Física e Química). Também apareceram como resposta o pouco tempo para 
estudo, as dificuldades com a escrita e a própria compreensão dos conteúdos a serem abordados em sala de aula. Segue algumas falas:

As principais dificuldades foram tentar relacionar as matérias de física, química e biologia de forma interdisciplinar e através dos conceitos para fazer os planos de aula, pois tem conteúdos que é fácil de articular, já outros fica impossível (Estagiário $6)$.

Interdisciplinaridade, pouco tempo para estudar, escrever com coerência, compreender alguns conteúdos (Estagiário 3).

O curso Interdisciplinar em Educação do Campo - Ciências da Natureza Licenciatura prime pelo trabalho docente, articulando os saberes sistematizados aos saberes que se enlaçam às práticas dos sujeitos que vivem no campo. Para tanto, indica como princípios metodológicos: o diálogo, a problematização, a contextualização, a interdisciplinaridade, a relação teoria-prática, a humanização, a ética e o compromisso com a transformação (PPC, 2019).

Assim, ao longo do processo formativo dos acadêmicos o trabalho interdisciplinar é um constante desafio, tanto nos CCRs que compõe a matriz curricular do curso, quanto ao longo da realização dos Estágios Curriculares Supervisionados.

Apesar de o curso ser estruturado por componentes curriculares bem delimitados, é necessário criar espaços, tempos e processos para desenvolver propostas de intervenção pedagógica na perspectiva da interdisciplinaridade, concretizando, na prática, a atitude interdisciplinar (PPC, 2019).

A interdisciplinaridade permeia todo o curso. Os espaços e momentos utilizados para desenvolver a interdisciplinaridade, a interação curricular ocorre principalmente por meio dos Seminários Integradores. Esses seminários iniciam no primeiro período quando há a oferta do CCR "Seminário Integrador das Práticas Pedagógicas I” e seguem por todos os semestres do curso, quando os estudantes vivenciam o "Seminário Integrador das Práticas Pedagógicas VIII".

Os Seminários Integradores também têm a função de integralizar a carga horária destinada à Prática como Componente Curricular (PCCr). Convém ressaltar, que o planejamento, o desenvolvimento de ações e a avaliação dessas pressupõe o envolvimento de todos os componentes curriculares da fase, sendo esses componentes de Domínio Comum, do Domínio Conexo e do Domínio Específico, além de sistematizações realizadas no campo dos estágios curriculares.

Assim, no início de cada semestre, os professores que atuam em uma mesma turma, realizam um planejamento coletivo. Definem temas que serão trabalhos e como 
cada professor, em seu CCR, contribuirá para a compreensão da temática a ser trabalhada.

Além dos Seminários Integradores, os Estágio Supervisionados também são trabalhados de forma interdisciplinar e conduzidos por três docentes que constituem a área de Ciências da Natureza (Biologia, Física e Química).

No entanto, mesmo que o curso seja trabalhado numa perspectiva interdisciplinar, parte acadêmicos possuem dificuldade para articular os conteúdos dos componentes curriculares da área Ciências da Natureza. Essa, deve-se ao fato deles possuírem pouco domínio do conteúdo. Outro fator que interfere na interdisciplinaridade é a disciplinarização do conteúdo nas escolas campo de estágio as disciplinas ainda são trabalhadas de forma isolada e não por área de conhecimento.

Uma das principais razões que os acadêmicos envolvidos na pesquisa encontram dificuldade com a escrita e com a organização dos conteúdos, deve-se ao fato da falta do hábito de leitura e de horário de estudos, assim como, pela língua portuguesa não ser a língua materna, uma vez que 5 destes acadêmicos envolvidos na pesquisa serem de origem kaingang.

Quando questionados sobre a existência da articulação entre os componentes curriculares que constituem a área de Ciências da Natureza nas escolas campo de estágio, os acadêmicos foram unânimes em responder que não perceberam esta articulação.

\section{Muito pouco. Ou seja não foi possivel perceber (Estagiário 3).}

O que deu para perceber é que na escola não é trabalhado de forma interdisciplinar a biologia, física e química. São trabalhadas separadamente (Estagiário 4).

Apesar dos direcionamentos propostos pela Base Nacional Comum Curricular BNCC e pelos Referenciais propostos pela Secretaria Estadual de Educação do Estado do Rio Grande do Sul para as EEB referentes ao ensino por área do conhecimento, ainda as escolas permanecem trabalhando num modelo disciplinar, ou seja, com disciplinas isoladas e desvinculadas umas das outras.

Apesar da interdisciplinaridade estar presente nas propostas e as pesquisas indicarem diversos debates em cursos de formação continuada, estimulando os professores ao trabalho interdisciplinar, diversos fatores contribuem para que ela não ocorra. Dentre estes fatores pode-se observar a falta de um planejamento integrado entre os professores, a sobrecarga em sala de aula, o que dificulta tempo para os planejamentos. 
A forma como as escolas continuam organizando os componentes curriculares, em muitas situações, não permitem que os alunos estagiários desenvolvam suas aulas de forma interdisciplinar. Essa situação ficou evidente quando questionamos se os acadêmicos conseguiram trabalhar os conteúdos de biologia, física e química de forma articulada. Dos seis estudantes, três mencionaram que não e três conseguiram trabalhar parcialmente. Segue algumas falas:

Durante o estágio IV a maior parte não consegui, pois tinha que seguir o calendário de conteúdos da professora tentando o máximo possível voltado para a realidade dos alunos (Estagiário 2).

Foi possivel relacionar biologia com química. No entanto, foi pouca coisa, pois o tema não tinha relação um com o outro (Estagiário 3).

Não consegui pois tinha que seguir os conteúdos dos professores separadamente e planejei conforme os conteúdos das professoras (Estagiário 6).

Levando em consideração as falas acima, concordamos com Bockniak (1998) quando destaca que a interdisciplinaridade proporciona a integração de conteúdos, por exemplo de biologia com química, e atividades que compõem o currículo de determinado nível de ensino. No entanto, o autor reitera que os professores não conseguem avançar muito nesta perspectiva.

Quando questionados sobre quais eram as principais dificuldades encontradas durante o processo de planejamento das aulas do estágio, cinco alunos mencionaram o conteúdo a ser trabalhado em sala de aula e o estabelecimento de relações entre os mesmos. Apenas um acadêmico relatou dificuldade em relação à organização do plano de aula. Novamente evidenciou-se as dificuldades apresentadas pelos acadêmicos no que se refere aos conceitos a serem trabalhados durante as aulas, uma vez que os conteúdos trabalhados no Ensino Médio apresentam maior complexidade e exigem maior aprofundamento.

Para auxiliar no processo de elaboração dos planejamentos, os alunos estagiários fizeram uso dos seguintes materiais: livros didáticos (3), consulta a artigos científicos (3), vídeos (2), aula prática (1), não respondeu (1). Dois alunos estagiários também destacaram a importância dos professores orientadores de estágio da Universidade durante o processo de planejamento das aulas.

Também questionamos os alunos estagiários se eles fizeram uso de aulas práticas ao longo do desenvolvimento do estágio. Todos responderam que sim, eles desenvolveram atividades experimentais demonstrativas. 
Sim, fiz um experimento de solubilidade e substância polar e apolar, colocando água em um copo, depois colocando óleo e por fim detergente. Fiz também um experimento com materiais condutores e isolante, onde usei duas pilhas grandes, dois pedaços de fio condutor, uma lâmpada de lanterna e materiais como palito de dente, prego, borracha, plástico. (Estagiário 4).

Sim estou envolvendo, principalmente de fisica, sobre movimento e repouso e movimento constante, onde estou usando os alunos para os experimentos, onde eles fazem corridas e calcula de tempo, distância e velocidade. Química-modelos atômicos através da construção de cartazes (Estagiário 6).

Nos processos de ensino e de aprendizagem, deve haver situações de encontro, de diálogo, de desafios. É nesse sentido que se inserem as atividades experimentais no ensino, podendo ser mais um meio para a compreensão de fenômenos e para o desenvolvimento de conceitos, procedimentos e atitudes por parte dos alunos. Galiazzi et al. (2001) afirmam que as atividades experimentais no ensino de Ciências vêm sendo apontadas como um importante recurso no desenvolvimento de saberes conceituais, procedimentais e atitudinais. Gonçalves, Silva e Vilardi (2020) salientam que as atividades experimentais têm relevância por possibilitarem a construção do conhecimento partindo da relação com cotidiano.

As atividades experimentais podem ser desenvolvidas de diversos modos, com diferentes enfoques, permitindo, assim, que o professor trabalhe vários tipos de competências e habilidades de seus alunos. Esses enfoques abrangem desde a mera observação por parte do aluno, por exemplo, até a sua participação efetiva na escolha da atividade, do problema a ser solucionado e do procedimento experimental a ser adotado, conforme é destacado pelos autores Andrade (2010), Borges (2002), Pinho Alves (2000) e Rosa (2003).

O Laboratório de Demonstração, segundo Pinho Alves (2000) é um dos mais utilizados no ensino, tendo a função de ilustrar conteúdos trabalhados em sala de aula. Geralmente, a demonstração (atividade prática) é feita antes de iniciar o conteúdo como forma de despertar e motivar o estudante, ou então serve para ilustrar determinado fenômeno físico. Também procura despertar no estudante as habilidades da observação e reflexão. Gaspar e Monteiro (2005) destacam como vantagem do uso deste laboratório:

[...] a possibilidade de ser realizada com um único equipamento para todos os alunos, sem a necessidade de uma sala de laboratório específica, a possibilidade de ser utilizada em meio à apresentação teórica, sem quebra de continuidade da abordagem conceitual que está sendo trabalhada e, talvez o fator mais importante, a motivação ou interesse que desperta e que pode 
predispor os alunos para a aprendizagem. (GASPAR; MONTEIRO, 2005, p. 227)

As atividades realizadas no laboratório de demonstrações são de fácil execução, porém, como qualquer outra atividade experimental, requer o planejamento e organização prévios por parte do professor.

Já o laboratório didático investigativo, conforme Andrade (2010), tem como pressuposto o construtivismo. As atividades experimentais são tarefas investigativas. Pinho Alves (2000, p. 266) destaca a participação efetiva do aluno:

\begin{abstract}
Um processo de ensino que se inspire na concepção construtivista, não terá como justificar um papel passivo do estudante quando da realização de uma atividade experimental. [...]. No entanto, sua participação ativa deve ser entendida não apenas quando é exigida alguma tarefa motora, mas também no processo de negociação do saber. A possibilidade de agir no processo de negociação do saber é a característica mais importante dentro de uma visão construtivista.
\end{abstract}

Durante o trabalho é estabelecido um ambiente onde há interação entre professores e alunos, onde os estudantes trabalham de forma coletiva. Os alunos fazem levantamento de hipóteses, escolha do procedimento e realizam as medições. O professor tem papel de mediador, auxiliando os alunos na exploração dos fenômenos.

Moro (2016) destaca que as atividades experimentais são uma possibilidade para envolver os alunos e motivá-los, bem como, uma alternativa metodológica para o professor, que busca romper com o formalismo existente na estrutura curricular das escolas, onde os conteúdos estão listados em um programa que é seguido linearmente, sem idas e voltas, ou como se os aspectos mais importantes devessem ficar para o final. Estas idas e voltas ao trabalhar os conteúdos em sala de aula, de acordo com Moreira (2011) são importantes e podem acontecer quando os mesmos conceitos são abordados de diferentes formas (atividades experimentais, atividades computacionais).

Moreira (2011) também destaca que a maioria dos livros didáticos também é organizada desta forma linear e cronológica, começando do mais simples e terminando com o mais complexo. E essa organização linear não promove a diferenciação progressiva e a reconciliação integradora, importantes para a ocorrência da aprendizagem significativa.

\title{
5. CONSIDERAÇÕES FINAIS
}

Com o desenvolvimento dessa pesquisa percebeu-se uma preocupação por parte dos acadêmicos do estágio Supervisionado Curricular no Ensino Médio (estágio IV) do 
curso de Educação do Campo da UFFS - Campus de Erechim, referente às dificuldades na articulação das disciplinas de Biologia, Física e Química durante as aulas de estágio no Ensino Médio. Percebeu-se dificuldades relacionadas ao conteúdo e à articulação das três disciplinas que compõem a área das Ciências da Natureza. Também foi relevante observar que a articulação entre as três disciplinas não aconteceu de forma completa, seja em função dos conteúdos rígidos e fechados determinados nas escolas, seja pela dificuldade de aceitação de um trabalho integrado entre as disciplinas, já que em todas as escolas, são três professores distintos que ministram as três disciplinas, inclusive de forma isolada uma das outras.

Um ponto significativo elencado nas respostas dos estudantes foi o fato de todos mencionarem ter realizado atividades experimentais em suas aulas do estágio IV, destacando que as mesmas motivaram não apenas os estudantes, mas inclusive eles próprios. Parece haver a necessidade de desmistificar a ideia de que aulas experimentais só podem acontecer em laboratórios (que a maioria das escolas não possuem) e com materiais sofisticados que se quer existem nas escolas, principalmente as públicas.

A fala informal de muitos estagiários revela a satisfação pelo uso das atividades experimentais durante seus estágios em docência, sendo este o verdadeiro papel de um estágio: agregar novas metodologias e romper com o formalismo existente e a práticas centradas apenas em livros didáticos. Há sempre a necessidade de debates acerca das contribuições das atividades experimentais, sejam elas demonstrativas ou investigativas, para os processos de ensino e de aprendizagem, nas diferentes disciplinas do curso, afinal, a formação inicial de educadores tem pretensão de proporcionar ao aluno uma formação reflexiva dos processos de construção no ensino e na aprendizagem.

Portanto, para trabalhos futuros fica a sugestão de investigar a presença de atividades experimentais, reais e virtuais, nas aulas de ciências, tanto no ensino Fundamental como no Ensino Médio, bem como um trabalho direcionado, a importância da articulação entre as disciplinas da área da Ciências da Natureza e também com os demais componentes curriculares das escolas, destacando como as atividades experimentais podem propiciar a aprendizagem dos estudantes e, configurarem-se como um recurso a mais para as aulas dos professores, rompendo com a visão enraizada de que o livro didático é o guia para as aulas.

\section{REFERÊNCIAS}

ALVES, Karla dos Santos Guterres. A didática das ciências no Brasil: Um olhar sobre uma década (2003 - 2012). 2016, 172f. Tese (Doutorado em Educação em Ciências: Química da Vida e Saúde), Universidade Federal do Rio Grande do Sul, Porto Alegre, 2016. 
ANDRADE, Jorge Augusto Nascimento de. Contribuições formativas do laboratório didático de física sob o enfoque das racionalidades. 2010. 146 f. Dissertação (Mestrado em Educação para a Ciência), Faculdade de Ciências, Universidade Estadual Paulista, Bauru, 2010.

BITTAR, Marilena; NOGUEIRA, Renato Gomes. Um Estudo da Criação e Desenvolvimento de Licenciaturas em Matemática na Universidade Federal de Mato Grosso do Sul. Bolema, vol. 29, n.51, Rio Claro, Apr. 2015.

BOCHNIACK, Regina. Questionar o conhecimento: interdisciplinaridade na escola. 2 ed. Editora Layola. São Paulo, 1998.

BORGES, A. Tarciso. Novos Rumos para o Laboratório Escolar de Ciências. Caderno Brasileiro do Ensino de Física, Florianópolis, v. 19, n. 3, p. 291-313, dez 2002.

BRASIL. Ministério da Educação. Conselho Nacional da Educação. Lei 9394, de 20 de dezembro de 1996. Disponível em: <http://www.mec.gov.br/legis/pdf/LDB.pdf>. Acesso em: 16 mar. 2020.

BRASIL. Parecer CNE/CP 21/2001. Disponível in em: $<$ http://www.mec.gov.br/cne/pdf/021.pdf>. Acesso em: 16 mar. 2020.

BRASIL. Resolução CNE/CP 2/2002. Disponível em: $<$ http://www.mec.gov.br/cne/pdf/cp022002.pdf>. Acesso em: 16 mar. 2020.

BRASIL. Parecer CNE/CP 02/2015. Disponível em: $<$ http://portal.mec.gov.br/index.php?option=com_docman\&view=download\&alias $=176$ 25-parecer-cne-cp-2-2015-aprovado-9-junho-2015\&category_slug=junho-2015pdf\&Itemid=30192> . Acesso em: 16 mar. 2020.

BRASIL. Ministério da Educação. Secretaria da Educação Básica. Base Nacional Comum Curricular: Educação Infantil e Ensino Fundamental. Brasília, 2017.

CHARMAZ, Katry. A construção da teoria fundamentada: Guia prático para análises qualitativas. Porto Alegre: Artmed, 2009.

GALIAZZI, Maria do Carmo; ROCHA, Jusseli Maria de Barros; SCHMITZ, Luiz Carlos; SOUZA, Moacir Langoni de; GIESTA, Sérgio; GONÇALVES, Fábio Peres. Objetivos das atividades experimentais no ensino médio: a pesquisa coletiva como modo de formação de professores de ciências. Ciência \& Educação, Bauru, v. 7, n. 2, p. 249-263, 2001.

GASPAR, Alberto; MONTEIRO, Isabel Cristina de Castro. Atividades experimentais de demonstrações em sala de aula: uma análise segundo o referencial da teoria de Vygotsky. Investigações em Ensino de Ciências, Porto Alegre, v. 10, n. 2, p. 227-254, 2005.

GIBBS, Grabam. Análise de dados qualitativos. Porto Alegre: Atmed, 2009. 
GONÇALVES, Francisca Helen Cardoso; SILVA, Ana Carolina Araújo da; VILARDI, Luisa Gomes de Almeida. Os Desafios na Utilização do Laboratório de Ensino de Ciências pelos professores de Ciências da Natureza. Revista Insignare Scientia, v. 3, $\mathrm{n}^{\mathrm{o}} 2$, p. 274-291, 2020.

LISOVSKI, Lisandra Almeida. Organização e desenvolvimento do estágio curricular supervisionado na formação de professores de Biologia. Dissertação de Mestrado. (Mestrado em Educação). Universidade Federal de Santa Maria, Santa Maria, 2006.

MOREIRA, Marco Antônio. Aprendizagem Significativa: a teoria e textos complementares. São Paulo: Livraria da Física, 2011.

MORO, Fernanda Teresa; NEIDE, Italo Gabriel; REHFELDT, Marcia Jussara Hepp. Atividades experimentais e simulações computacionais: integração para a construção de conceitos de transferência de energia térmica no ensino médio. Caderno Brasileiro de Ensino de Física, v. 33, n. 3, p. 987-1008, dez. 2016.

PEREIRA, Júlio Emílio Diniz. As licenciaturas e as novas políticas educacionais para a formação docente. Educação \& Sociedade, ano XX, nº 68, p. 109 a 125, dez. 1999.

PINHO ALVES, José Filho. Atividades experimentais: do método à prática construtivista. 2000. 302 f. Tese (Doutorado em Ensino de Ciências Naturais) - Centro de Ciências da Educação, Universidade Federal de Santa Catarina, Florianópolis, 2000.

ROSA, Cleci Werner da. Concepções metodológicas no laboratório didático de física na Universidade de Passo Fundo. Ensaio Pesquisa em Educação em Ciências, v. 5, n. 2, p. 13-27, out. 2003.

TANURI, Leonor Maria. História da Formação de Professores. Revista Brasileira de Educação, Campinas, n. 14, Mai, 2000. p. 61-88.

TERRAZZAN, Eduardo Adolfo. Necessidades e perspectivas para os novos estágios curriculares na formação de professores: primeiras aproximações. In: SELLES, Sandra Lucia Escovedo; FERREIRA, Marcia Serra. Formação docente: memórias e práticas. Niterói: Eduff, 2003. 